\title{
NOBELPREIS - DIE TCM LIEFERT \\ NEUE ERKENNTNISSE ZU ALTEN QUELLEN
}

\section{Sehr geehrte Frau Kollegin! \\ Sehr geehrter Herr Kollege!}

Wie jedes Jahr um diese Zeit dürfen wir Ihnen ein Österreicher-Heft vorlegen.Viele für die Praxis relevante Artikel haben wir für Sie vorbereitet. Doch in diesem Jahr werden alle unsere Beiträge überstrahlt von einem einzigartigen Ereignis: Der Zuerkennung des Nobelpreises für Medizin für ein erfolgreiches Forschungsprojekt aus der TCM. Noch nie zuvor hat eine Forschungsarbeit aus der TCM einen Nobelpreis erreichen können. Doch in diesem Jahr wurde die Malariatherapie mit Artemisinin mit diesem höchsten medizinischen Preis ausgezeichnet, worüber wir uns außerordentlich freuen. Nicht nur über die Ehre und Anerkennung, die damit der TCM entgegengebracht wird, sondern auch in der Hoffnung, dass zunehmend Wissen aus der TCM in unsere westliche Medizin übernommen wird. Denn immer schon war unsere Philosophie nicht das Gegeneinander, sondern das Miteinander und die Kombination dieser unterschiedlichen, medizinischen Welten. Die Auszeichnung mit dem Nobelpreis kann ein weiterer Schritt in diese unseres Erachtens richtige Richtung sein. Wir gratulieren den chinesischen Kolleginnen und Kollegen ganz herzlich und wünschen weiterhin viel Erfolg und Anerkennung für die zukünftigen Forschungsprojekte.
Ich lade Sie herzlich zur Lektüre unserer ÖsterreicherBeiträge ein: Von der exakten Beschreibung eines Hypnoakupunktur-Falles mit chronischem Schmerzsyndrom über Tuina und Gynäkologie bis hin zu einer neuen Methode aus der frequenziellen Akupunktur spannt sich der Bogen, so dass hoffentlich für jede Leserin und jeden Leser Interessantes dabei ist. Lassen Sie sich von unseren Ideen und Erkenntnissen inspirieren!

Ich darf Ihnen abschließend noch eine entspannende und schöne Weihnachtszeit und auch im Jahr 2016 viel Freude mit der Aurikulomedizin und TCM wünschen

Ihr

Prof. Dr. med. Leopold Dorfer

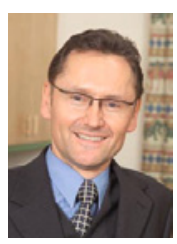

Prof. Dr. med. Leopold Dorfer

Präsident der Österreichischen Gesellschaft für Kontrollierte Akupunktur und TCM (OGKA)

Glacisstraße 7, A-8010 Graz

Tel. $+43316 / 374050$

E-Mail: office@ogka.at, Internet:www.ogka.at 